\title{
The Canadian context
}

\section{for evidence-based conservation and environmental management}

\author{
Steven J. Cooke ${ }^{1,2^{*}} \mathbb{D}$, Jake C. Rice ${ }^{3}$, Kent A. Prior ${ }^{4}$, Robin Bloom ${ }^{5}$, Olaf Jensen ${ }^{6}$, David R. Browne', \\ Lisa A. Donaldson ${ }^{1,2}$, Joseph R. Bennett ${ }^{1,8}$, Jesse C. Vermaire ${ }^{1,9}$ and Graeme Auld ${ }^{1,10}$
}

\begin{abstract}
Canada has strong institutional capacity for science-based decision-making related to natural resource conservation and environmental management. Yet, the concept of using systematic reviews (conducted in accordance with established guidelines) to support evidence-based conservation and environmental management in Canada is in its infancy. Here we discuss the Canadian context for implementing more rigorous evidence-based approaches using systematic reviews. Of particular relevance to Canada is its vast size, broad diversity of ecosystems and heavy economic reliance on natural resources that vary widely in the type and scale of their environmental effects. These factors result in a wide variety of environmental monitoring needs over an extensive area that pose challenges to the scientific community charged with overseeing wise use of the environment. In addition, there are diverse and engaged user groups (e.g., hunters, trappers, fishers, bird watchers, foresters) and indigenous peoples that have constitutional rights to their natural resources. Traditional environmental knowledge is a complementary source of evidence in the Canadian environmental impact assessment process and therefore must be a part of evidence synthesis. Systematic reviews are not intended to replace local field studies, but rather have the opportunity to draw upon a broader suite of evidence that can be interfaced with local perspectives. The existing institutional structures in Canada could easily incorporate systematic reviews into their science advice and decision-making frameworks but to date, there are few examples of where this has occurred. Drawing on the expertise of a growing global collaboration for environmental evidence synthesis, Canadian institutions (federal, provincial and NGO) are poised to more broadly incorporate systematic reviews once their benefits are fully realized and the capacity to undertake such systematic reviews is fully developed. Systematic reviews offer a consolidated view of the available scientific literature on a given question. The results may offer significant value when working with stakeholders and decision makers contributing other sources of information to the question. For example, mechanisms to capture and integrate scientific knowledge with stakeholder and traditional knowledge may benefit from the scientific sources being filtered, interpreted and summarized for discussion. In other cases, where timeframes for decision making preclude formal systematic reviews, opportunities for more rapid evidence synthesis methods will be needed before the concept will be fully embraced.
\end{abstract}

Keywords: Canada, Evidence, Decision-making, Science-Policy Interface, Conservation, Resource management

\section{Background}

Although for decades the concept of critical and systematic synthesis of information has served as the basis for an evidence-based approach to global health care (i.e.,

\footnotetext{
*Correspondence: Steven_Cooke@carleton.ca

${ }^{1}$ Canadian Centre for Evidence-Based Conservation and Environmental

Management, Carleton University, Ottawa, ON, Canada

Full list of author information is available at the end of the article
}

systematic reviews through the Cochrane Collaboration; [1]), it is a reasonably new concept to be embraced by the environmental management and conservation communities [2]. The premise is simple: environmental managers and conservation practitioners are not making systematic use of the full suite of available information to base their decisions, policy, and actions [3]. Indeed, a survey of land managers in the United Kingdom revealed that 
practitioners tended to base their decisions and actions on tradition and experience rather than the evidence base available to them [4]. The concept of an evidence-based approach to environmental management and conservation involves using systematic reviews to assemble, critically evaluate and synthesize the evidence. For the purpose of this paper we embrace the language and spirit of the Collaboration for Environmental Evidence (CEE) and note that their guidelines for systematic review (see http://www. environmentalevidence.org/information-for-authors) represent the highest standard of evidence synthesis. It is possible to follow some aspects of the CEE guidelines to conduct a "modified systematic review" but reliability, transparency, and repeatability are diminished if the CEE guidelines are not adhered to in their entirety. Hence, some so-called systematic reviews represent a less reliable evidence synthesis activity if CEE guidelines were not followed. Synthesis may involve quantitative meta-analysis methods, narrative approaches, or mixed methods (a combination of both quantitative and qualitative analyses). [5]. In either case the resulting synthesis identifies patterns and trends that can be exploited to guide practitioners toward actions that are "doing more good than harm" [6].

Efforts are still in their infancy in Canada with respect to developing capacity to conduct systematic reviews for conservation and environmental management purposes as well as identifying mechanisms by which the outcomes of such reviews can be used by various bodies (especially government natural resource management and environmental regulatory agencies but also industry). Nonetheless, such efforts are underway. Here, we provide a brief perspective on the Canadian context for evidence-based conservation and environmental management. We start by describing the Canadian environmental management context. We then provide an overview of the current means by which science advice is used to inform management within three Canadian federal agencies with portfolios directly related to environmental management. Next, we provide a window on the role of environmental nongovernmental organizations in development of evidencebased practices and policy. We conclude by considering the Canadian context that creates both opportunities and challenges for operationalizing an evidence-based approach to conservation and environment-management in Canada.

\section{Canada}

Canada is comprised of 10 provinces and 3 territories that cover $9,984,670 \mathrm{~km}^{2}$, making it the second largest country in the world. Despite its size, Canada's population is relatively small at $\sim 35$ million people and when adjusted for population density, it ranks near the least dense of all nations (ranking 228th globally). Canada has some
$202,080 \mathrm{~km}$ of coastline as well as some $891,163 \mathrm{~km}^{2}$ of freshwater surface area (including the massive Laurentian Great Lakes), 7 \% of the world's renewable freshwater resources and $22 \%$ of global wetlands. The climate is diverse with distinct seasons, varying from temperate in the south to sub-Arctic and Arctic in the north. Much of Canada is forested (e.g., Boreal regions) representing $9 \%$ of the world's forest cover.

Canada is considered a developed country, nominally the 9th wealthiest in the world, and operates as a parliamentary democracy. Given the rich natural resource base (both renewable and non-renewable) in Canada, the natural resource sector is important to the economy and livelihoods. In general, natural resource use and extraction is rather heavily regulated (in a comparative sense to other jurisdictions) in an effort to ensure that extraction is sustainable. Forest products (especially pulp and paper), fisheries products (marine and inland), aggregate resources, minerals (e.g., nickel, cadmium, diamonds, gold, iron ore), fossil fuels (on land and under the sea), and harnessing water for hydroelectricity all represent important industrial activities. There is also substantial economic benefit derived from Canadians and tourists that visit the Canadian wilderness where they hunt, fish, bird watch, canoe, camp, snowshoe, ski, etc. Regionally (e.g., in the prairie provinces), agriculture is a prominent land use. According to the Committee on the Status of Endangered Wildlife in Canada, currently there are 660 species at various degrees of risk in Canada with the majority of these occurring in southern British Columbia, Ontario, and Quebec.

For millennia, indigenous peoples populated the landscape now known as Canada. European settlers landed in the 1500s (largely French and British), transformed the landscape quickly and changed the cultural trajectory of indigenous peoples forever. Today, although a small proportion of Canada's total population ( $4 \%)$, First Nations, Metis and Inuit peoples (collectively called indigenous peoples) play an important role in society with treaty rights guaranteed under the constitution (e.g., the right to access fish for food and ceremonial purposes) that must be taken into account in Canadian natural resource management. Aside from indigenous peoples, Canada is a land of immigrants with incredible cultural diversity, ranking first among 21 'western' countries on the Cultural Diversity Index [7].

\section{The environmental governance and regulatory landscape}

The Canadian governance and regulatory landscape for many environmental and natural resource management issues is highly decentralized, with important constitutional powers relevant to these fields of regulation 
residing with provinces. The 1867 British North America (BNA) Act established the jurisdictional divisions of powers, with some significant amendments relevant to resource management added (section 92A, or the resource amendment) with the enactment of the Constitution Act of 1982. Section 109 of the BNA Act granted the provinces ownership of land and resources, a power that has been extended to other provinces as they joined confederation. Provinces also hold powers to make laws affecting the management and sale of provincially-owned public lands and any timber resources these lands produced [section 92(5)], yet they were only given power for direct taxation within their respective provincial territories [section 92(2)]. The federal government holds more exclusive rights to make laws concerning fisheries resources [section 91(10) on 'Navigation and Shipping' and 91(12) on 'Sea Coast and Inland Fisheries'], and it holds some power over natural resources through its powers to regulate trade and commerce [section 91(2)] and its powers to raise "Money by any Mode or System of Taxation" [section 91(3)] (Government of Canada, 2013). The resource amendment (section 92A) was added to the Constitution Act of 1982 to clarify and deepen provincial powers to set laws for non-renewable and renewable resources and electricity production, as well as the power to make money from these resources by any means. Among the powers retained by the federal government are responsibility for matters of international concern, treaties and conventions associated with them and national legislation for their implementation. Examples are the Migratory Birds Convention (1916), the Convention on International Trade of Endangered Species of Wild Flora and Fauna (1973) and the Convention on Biological Diversity (1992).

The division of powers has demanded considerable cooperation among the provinces and territories, and between the federal government and the provinces and territories on many environment and natural resource related issues. Recent efforts by the federal government to delegate authority to the territories have given the territories a growing importance on environment and natural resource policy matters as well. Despite their importance as homes for the vast majority of Canadians, cities (i.e., municipal or regional governments) have no constitutional powers; their regulatory authority flows from provincial legislation that delegates them specific powers and responsibilities. Finally, evolving constitutional jurisprudence has granted a growing governance role to Canadian indigenous peoples owing to court interpretation of the government's treaty obligations and due to section 35 of the Constitution Act of 1982 that recognized the existence of indigenous and treaty rights in Canada. This changing jurisprudence means few natural resource and environmental regulatory processes can operate without consultation and involvement of indigenous peoples.

Below, we describe the extent to which three federal agencies that are responsible for natural resource management, currently use various forms of evidence to support decision-making. Each agency has a complex mandate that can interact with the mandates of additional federal, provincial, indigenous or municipal decision-makers. For example, the department of Fisheries and Oceans (DFO), whose mandate is to manage fisheries and safeguard waters, must determine management strategies for resources that cross both provincial and international boundaries, and are also subject to a mix of local and constitutional indigenous rights [8]. Environment and Climate Change Canada has an extremely broad mandate that includes regulatory responsibilities for air, water and biodiversity. Parks Canada, a separate agency that reports to the Minister of Environment and Climate Change, is mandated with protecting the natural and cultural heritage of sites throughout Canada. The complex mandates of these agencies necessitate the use of transparent and informed approaches to decisionmaking. However, all face challenges in implementing such approaches, in terms of gathering and synthesizing required information, and in terms of using this information to make decisions.

\section{Fisheries and Oceans Canada}

The use of evidence-based advice for policy and management is well-established in the DFO. Historically, the effectiveness of linking the results of such assessments to fisheries management decisions was often criticized as weak $[9,10]$. In response, formal methods of management strategy evaluations (MSEs) with explicit harvest control rules (HCRs) have become a standard practice for fisheries advice used by DFO. These MSEs and HCRs provide a quantitative link between the results and uncertainties in the assessments and the sustainable levels of harvests for management $[11,12]$.

Aquaculture, fish health and marine biotechnology form another class of activities regulated by DFO. Here the use of evidence must balance opportunities and risks. Research on new opportunities for culture or other commercial products that could be developed further includes testing growth and other productivity parameters of new species and strains, new food sources, and similar activities. Research on risks involves testing for pathogens and other by-products of culture and biotechnology, with regard to what hazards they may pose to natural ecosystems and how to avoid or mitigate the associated risks. New culture strains and transfer of strains among watershed are regulated, as are moving 
biotechnology products into commercial applications. All the respective regulatory decision-making processes have standards of science codified, to help ensure the use of science in management practices.

Another area of DFO activity concerns potential impacts of human activities on the fisheries productivity of aquatic habitats, and developing options to avoid or mitigate negative impacts [13]. Under the previous "no net loss" habitat policy [14], the evidence needed to inform case by case decisions on approval of activities that would have impacts on aquatic habitats was only delineated in a general way, although the standard of tolerance of impacts (i.e., no net loss] was explicit. The aggregate outcome of the case-specific decisions fell far short of "no net loss" of aquatic habitats [15]. The framework for implementation of the new Fishery Protection Provisions of the Fisheries Act are more strongly evidence-based [16], but the tools for using existing evidence and augmenting the shortcomings in the relevant databases are still under development.

In all these roles, DFO needs science advice (which is somewhat different from the strict sense of "evidence" associated with a SR) to inform policy and management decisions, and the processes for provision of that advice have been through several changes. In 1996/7 DFO established what is now called the Canadian Science Advisory Secretariat (CSAS). As initially established, scientific rigour was complemented by high inclusiveness and transparency. Codified operational procedures included:

- Between a quarter and a third of participants at each challenge-format peer review and advisory meeting were to be invited experts from outside government, including holders of indigenous and local knowledge;

- Adjournment of each advisory meeting was followed by a press conference, with the meeting chair, a representative of CSAS, and a third person chosen by meeting participants briefing the media on the consensus scientific conclusions;

- A target of having a finalized Science Advisory Report to translation within 14 days of meeting adjournment, and e-publication as soon as the advisory report was available in both official languages.

When the Canadian Species at Risk Act came into effect in 2002, CSAS led the Department in developing the processes for reviewing potential species prior to being considered for listing, and recovery potential assessments and incidental harm permitting (see DFO 2002, CSAS Proceedings 2002/35; Proceedings of the National Science Review Meeting on Species at Risk Issues; December 9-13, 2002.). Similar initiatives were taken for implementation of relevant parts of the Oceans
Act, such that when requests for advice on issues like impacts of seismic testing on marine animals, or what marine areas were particularly "ecologically or biologically significant", the science frameworks for responding to requests were already in place.

\section{Environment and Climate Change Canada}

Environment and Climate Change Canada's 2014-2019 Science Strategy (http://www.ec.gc.ca/scitech/default.asp? lang $=$ en $\& n=72 C 52 D 55-1)$ emphasizes the need for science that is relevant, effective and efficient and directs the Department to ensure that Departmental activities are based on the best available scientific evidence. Environment and Climate Change Canada's foray into use of some elements of systematic review was in response to a 2005 proposal to drill shallow gas wells within a protected area that supports several nationally threatened and endangered species. Evidence synthesis was undertaken by Environment and Climate Change Canada between 2006 and 2010 in an effort to understand the environmental impacts of the proposed project as part of an internal process (i.e., the synthesis was not published and was used to support internal decision-making).

A modified systematic review (adopting some elements of the formal CEE guidelines but not including a review of the protocol) approach was employed to assess the outcome of several 'interventions' on a shortlist of "valuable ecosystem components" (VEC). In this case VEC's were groups of wildlife populations of concern: the grassland bird community, herptile community, the endangered Ord's Kangaroo rat and Pronghorn antelope. A Joint federal-provincial Review Panel (JRP) was charged with assessing the potential for significant environmental effects (cumulative environmental effects) as the result of drilling the proposed natural gas wells in the protected area.

The effects assessment framework corresponds to the main elements of systematic review questions: each test for an effect consists of a receptor population (wildlife in this case), intervention/exposure factors (in this case, the various pathways by which gas extraction effects wildlife) and outcome (the evidence for a positive, negative or neutral effect of a given intervention). Given the alignment of SR methodology to the circumstances, Environment and Climate Change Canada undertook a modified-SR approach to offer the JRP advice on the cumulative effects of the project (see [17]) as estimated from a systematic review of the individual effects, metaanalysis of the results and narrative examination of the evidence for potential combined effects.

The quantitative assessment of cumulative effects is very difficult because it would rely on a measure of the 
ecosystem in its current or past unaltered state, a measure of the range of natural variability, a measure of the quantitative effects of the project itself, and a quantification of some threshold beyond which the project, in combination with other projects, would have significant adverse effects. These measures would have to be sufficiently precise and include a measure of variance to allow some level of modeling using alternative scenarios. The complexity and enormity of this undertaking has resulted in cumulative effects assessment being both reductionist and narrative in nature.

While the reductionist approach has merit in the assessment of cumulative effects, it can be difficult for a decision making or recommending body to make objective decisions based on all narrative reviews because of their subjective nature [18]. The subjective nature of the presentation of results from a narrative review can be a mixture of opinion and fact, and while another body or person may posit an alternative opinion it is exceedingly difficult for a decision making body, which is both naïve and neutral by nature, to divine the truth from these points of view. Systematic review, including its format for the presentation of results, is a much more objective means of assessing cumulative effects and inherently more useful to a decision making body charged with reviewing complex material.

Environmental assessment boards are faced with the difficult task of evaluating a significant volume of material that is often contradictory [18]. In the past, the evidence presented to these boards has been experiencebased (including narrative reviews provided by contracted professionals; [18]). It is difficult to assess these conflicting views in a consistent, systematic, and objective fashion. The decisions that result from these assessments are invariably subjective themselves since the information must be evaluated and parsed through the subjective lens of the board members themselves: decisions based on personal experiences and knowledge of traditional or conventional approaches [19]. Systematic reviews conducted to CEE standards offer a solution in that they facilitate the presentation of information that is transparent, particularly in decisions on the inclusion of studies and subsequent interpretation of effect sizes. Conservation actions based on these systematic reviews are defensible and rational as they offer a traceable source of evidence and repeatable methodology. It is anticipated that systematic reviews will become a more formalized component of environmental assessments in the future.

\section{Parks Canada}

Parks Canada is responsible for the establishment, protection and presentation of nationally significant examples of Canada's natural and cultural heritage. This includes 46 national parks and reserves, 3 national marine conservation areas and 973 national historic sites.

Concerning natural heritage, the Parks Canada charter highlights a commitment to the protection of ecological integrity, unimpaired for present and future generations, as a first priority. To meet this pledge the agency is guided by a set of principles:

- The integrity of natural heritage is maintained by striving to ensure that management decisions are made on sound resource management and ecosystem-based management practices;

- Decision-making must be based on an understanding of the surrounding environments and their management;

- Management decisions are based on the best available knowledge, supported by a wide range of research, including a commitment to integrated scientific monitoring;

- Ecosystem management must be credible, and therefore, solidly based in science;

- Management must be guided by the rigorous application of science;

- Decision-making associated with the protection of park ecosystems will be scientifically based on internationally accepted principles and concepts of conservation biology;

- Where manipulation is necessary it will be based on scientific research.

Given their directive tone, these principles must be applied. However, Parks Canada lacks a transparent double-check mechanism that could ensure such principles-e.g., consideration of existing knowledge, local empirical data and thorough review of evidence-are being followed in a standard manner.

At the scale of individual parks, Parks Canada requires the preparation of a site vision, overall objectives and ecological integrity indicators as part of a park management plan. In addition, management interventions to protect ecological integrity are to be informed by local baseline environmental monitoring data. Collectively, these planning perspectives and data are used to determine the status and trend of parks and thus the necessity to intervene (http://www.pc.gc.ca/eng/progs/np-pn/ie-ei. aspx).

Further, the agency led development of principles and guidelines specifically aimed at the practice of ecological restoration (subsequently adopted by IUCN), which emphasize an adaptive management approach to problem definition, monitoring, and strategy revision based on quantitative and qualitative information (http://www. pc.gc.ca/eng/progs/np-pn/re-er/pag-pel.aspx). Especially 
acute threats to the ecological integrity of Canada's national parks have also warranted specific management directives, which explicitly require the application of evidence to inform practice.

The strong regulatory foundation and recent commitments by the federal government to advance evidencebased decision-making (http://www.pc.gc.ca/eng/ minister-environment-and-climate-change-mandate-letter) suggest that Parks Canada is positioned to spearhead the use of evidence to manage protected areas. The seeds of such a modernization are already germinating in two areas.

First, Parks Canada is collaborating with the Canadian Centre for Evidence-Based Conservation and Environmental Management in a systematic review of methods used to eradicate undesirable non-native fish. Open access publication of the project results will enable (i) managers to select more effective methods to remove freshwater fish and (ii) the identification of information gaps that could be filled through controlled field experiments. No less important, this work will also allow Parks Canada and the Canadian Centre for EvidenceBased Conservation and Environmental Management to gauge the practicality of conducting systematic reviews to inform government policy and operations. The project will help determine whether such a strict approach to evaluate evidence can yield insights that are timely, applicable and cost-effective for government agencies like Parks Canada.

Second, Parks Canada recently completed a narrative review of the effectiveness of marine protected area (MPA) management through voluntary measures, as an alternative or in addition to legislated regulations for conservation. The review revealed that effectiveness of voluntary measures is very rarely analysed, and of the few studies that assessed effectiveness, less than a quarter pointed to successful outcomes. The key factors that were identified for the success of voluntary measures included community support, various socio-economic factors affecting compliance, and good governance factors such as legitimacy, leadership, and a perception of fairness. In order to improve efficacy of voluntary measures for MPAs, empirical research is needed to establish effective circumstances where, when, and how voluntary measures can be applied to address management objectives-a valuable conclusion from this systematic review (albeit not following all CEE standards).

\section{The role of $\mathrm{NGOs}$}

The environmental and conservation non-governmental organization (NGO) sector in Canada ranges from land trusts, to use-based groups such as hunting and angling associations, to naturalist clubs and organizations, to public engagement and advocacy groups formed around specific issues. Organizations also range in scale from entirely volunteer run to large national organizations with substantial staff and science capacity. Many of the organizations in the sector are focused on achieving specific environmental or wildlife conservation outcomes through either on-the-ground action or the adoption of policies and regulations at the municipal, provincial or federal level. A common thread in many organizations is the desire to do more good than harm by basing both onthe-ground actions and policy advice on strong science. Furthermore, in many cases NGOs will be the primary end user of evidence-based conservation techniques (especially for lands they manage) that are standardized through the systematic review process. This is increasingly the case in Canada as the governmental sector continues to shift away from on-the-ground conservation action to focus primarily on regulation with conservation actions delivered through partnerships with civil society actors. NGOs harness a sector of society that wants to see positive outcomes for the environment and wildlife and as such have a vested interest in a national evidencebased approach that identifies the best possible tools and techniques for specific environmental or conservation challenges.

NGOs in Canada are likely similar to the natural resource management sector in their degree of reliance on tradition and experience rather than evidence with perhaps some types of organizations even less reliant on the evidence base due to lack of access to current research (access to search databases and peer reviewed publications is expensive) and lack of a strong community of practice. That being noted, NGOs have three primary roles in the development of evidence-based conservation in Canada: (1) NGOs interact with a large portion of Canadian society and can help create a national climate in which the public expects an evidence based approach and understands the role of science in environmental and wildlife management; (2) NGOs have expertise ranging from species at risk recovery techniques to enhancement of habitat for fish and wildlife. They play a role in identifying conservation problems that lack an evidence base and in contributing expert knowledge to a systematic review; and (3) NGOs can play a role in justifying the need for a review and in bringing private funders to the project.

It is our contention that not only is an evidencebased approach to environmental management and conservation critical to a robust and effective non-governmental sector, but that engagement and participation of the non-governmental sector will be critical to the success of an evidence-based approach in Canada. This will be particularly relevant in the early stages of 
building capacity for conducting SRs in Canada as well as developing and expanding institutional mechanisms by which SRs become the basis for evidence-informed decision-making.

\section{Integration}

The Canadian context creates both opportunities and challenges for operationalizing an evidence-based approach to conservation and environmental management in Canada. Here we briefly summarize several realities for fully embracing an evidence-based approach to conservation and environmental management based on the systematic review platform.

\section{Resource-rich growth economy}

As noted above, Canada has rich natural resources that support the economy through extensive international trade and export. Much of the Canadian north is perceived as "frontier" territory going back to the era of the Yukon gold rush and the Hudson's Bay Company. At times, the ingenuity and creativeness of those that exploit those resources outpaces our understanding of how to manage these activities consistent with principles of environmental sustainability. Whether it be development of hydrokinetic turbines in coastal zones to capture tidal energy, hydraulic fracturing to extract oil from the ground, installation of small run of the river hydropower facilities on hundreds of rivers, or mining of diamonds in areas with permafrost, there remains a paucity of empirical research to inform development activities and associated mitigation and compensation. With emerging threats and opportunities, there is great need to provide science advice to managers and policy makers [20]. Using systematic reviews of the global literature can help to establish a more credible evidence base while also identifying knowledge gaps which bring uncertainty to decision-making and making use of limited "local" empirical evidence [21].

\section{Canada is big}

Although Canada has many institutions of higher learning and relatively well-funded and well-resourced natural resource management agencies, the vast size of the physical landscape inherently limits capacity for field research and site visits. For example, there are orders of magnitude more lakes than aquatic biologists. Thus, natural resource management decisions often have to be made on a landscape level (e.g., [22]). Although this is a practical and necessary approach, site-specific variation is thus not accounted for in many instances. Using SRs and incorporating regional data (from technical reports) along with other (more global) information sources could provide managers with more explicit direction (see [23]), especially when managing resources for which there may be little known about population status, trends and demography_or perhaps an emerging contaminant.

\section{Decision-making timelines}

Regulatory bodies are expected to respond to various development proposals and other issues in a timely manner [24]. Moreover, politicians expect "quick answers" from their science support staff. Systematic reviews take time (often more than 1 year) to conduct properly if following the CEE SR guidelines. This timeline may simply be too protracted to be useful for time-sensitive decisions (such as the examples related to resource extraction noted above). However, time-sensitive "localized" issues often grow to become broader issues that will benefit from longer-term views of evidence synthesis. Nonetheless, in Canada (and presumably elsewhere) there is a need for rapid evidence synthesis protocols that attempt to maintain credibility, rigour, and transparency recognizing that it will be unlikely to be as thorough and thus reliable as a SR conducted to CEE standards. Efforts to develop accepted protocols for rapid evidence synthesis would enable management agencies to better incorporate evidence-based approaches into decisions in a timely manner.

\section{Stakeholders and traditional knowledge}

Stakeholder and traditional knowledge is regarded as a valuable source of information related to environmental management and conservation [25]. In jurisdictions such as Canada with strong indigenous communities, which hold legal rights over the development of their land, there is both moral and legal imperative for seeking, valuing and using traditional knowledge for environmental management and conservation. Nonetheless, there remain significant challenges in reconciling those knowledge sources with peer-reviewed science [26]. For the Canadian context, there needs to be well-defined processes that explicitly include both stakeholder and traditional knowledge alongside the more conventional scientific evidence. The current systematic review protocols from the CEE (see [27]) certainly encourage engagement with diverse stakeholders. Yet, the mechanisms for the formal incorporation of traditional or somatic tacit knowledge into some aspects of SR (e.g., when measuring effect sizes) remain challenging. Qualitative data arising from traditional and somatic sources can be used to generate hypotheses that can be tested with quantitative or experimental data [28]. For now, SR can offer consolidated views of the available scientific knowledge to be considered alongside other knowledge sources such as customary and traditional knowledge systems. 


\section{Traditions and change}

Many of environmental and natural resource management agencies in Canada have developed the management tools and science advice mechanisms (e.g., the Canadian Science Advisory Secretariat within DFO) that are employed in Canada and other jurisdictions. How often are those tools revisited or questioned relative to the availability of new evidence? SRs have the potential to support existing management actions or identify those that need to be rethought based on a critical review of the totality of the evidence. There is no doubt that natural resource agencies and the professionals that work for them are committed in spirit to sustainable environmental management and conservation. An evidence-based, transparent process for decision-making would help to ensure the actions chosen are the ones most likely to achieve the desired outcome.

\section{Towards a new vision of evidence-based conservation and environmental management in Canada}

Our team of authors from different backgrounds (i.e., aquatic science, science policy, ecosystem restoration, regulation of contaminants) and institutions (i.e., academia, government, NGO) all see merit and opportunity for incorporating an evidence-based approach based on systematic reviews (that ideally follow the CEE guidelines) to promote effective evidence-based conservation and environmental management in Canada. This is not to suggest that current decisions are not science-based or made with the best of intentions. Quite simply, systematic reviews provide an additional level of rigour, repeatability and certainty to inform decision making. In our opinion, an organized, global, and transparent systematic review process such as carried out by the Cochrane Collaboration in medicine and spearheaded by the CEE in environment and conservation offers the most robust method for building a decision making structure and fostering a culture of evidence-based management. At its core the adoption of a structured systematic review based approach to conservation and environmental management offers three significant advantages over the status quo:

(1) Transparency: The Collaboration for Environmental Evidence offers a highly transparent method for carrying out systematic reviews. Decision making during the review process is well documented and available to the reader.

(2) Accessibility: Systematic reviews are free to access and are widely available from a central location so interested parties know where to access them such as through the Collaboration for Environmental Evidence.
(3) Consistency: the systematic review process is highly structured and the repeatability and comparability among reviews will help managers and practitioners better interpret the results of reviews.

The Canadian context (as described above) creates challenges, but at this juncture, the biggest challenges relate to awareness of SRs and a capacity to conduct them (properly-i.e., in accordance with CEE guidelines). The existing institutional structures are well-suited to the integration of SRs into their current science advice and decision-making processes, mindful of the fact that SRs are not regarded as particularly fast methods of evidence synthesis. Horizon scans to identify emerging issues can be used to inform SR prioritization and proactively synthesize evidence before issues demand rapid action. Moving forward, the Canadian Centre for Evidence-Based Conservation and Environmental Management and its partners will need to work together to help address these aforementioned challenges and help to implement SRs within the existing Canadian context.

\begin{abstract}
Abbreviations
BNA: British North America (Act); CEE: collaboration for environmental evidence; CSAS: Canadian Science Advisory Secretariat; DFO: Fisheries and Oceans Canada; ECCC: Environment Canada and Climate Change; IUCN: International Union for the Conservation of Nature; JRP: joint review panel; NGO: Non-Governmental Organization; MPA: marine protected area; SR: systematic review; VEC: valuable ecosystem component.
\end{abstract}

\section{Authors' contributions}

SJC conceived the idea for the manuscript and assembled the team of coauthors. All co-authors contributed to framing the paper, writing, and revision. All authors read and approved the final manuscript.

\section{Author details}

${ }^{1}$ Canadian Centre for Evidence-Based Conservation and Environmental Management, Carleton University, Ottawa, ON, Canada. ${ }^{2}$ Fish Ecology and Conservation Physiology Laboratory, Department of Biology and Institute of Environmental Science, Carleton University, Ottawa, ON, Canada. ${ }^{3}$ Canadian Science Advisory Secretariat, Fisheries and Oceans Canada, Ottawa, ON, Canada. ${ }^{4}$ Ecosystem Restoration, Parks Canada Agency, Gatineau, QC, Canada. ${ }^{5}$ Canadian Wildlife Service, Environment and Climate Change Canada, Edmonton, AB, Canada. ${ }^{6}$ Canadian Wildlife Service, Environment and Climate Change Canada, Gatineau, QC, Canada. ${ }^{7}$ Canadian Wildlife Federation, Ottawa, ON, Canada. ${ }^{8}$ Department of Biology and Institute of Environmental Science, Carleton University, Ottawa, ON, Canada. ${ }^{9}$ Department of Geography and Environmental Studies and Institute of Environmental Science, Carleton University, Ottawa, ON, Canada. ${ }^{10}$ School of Public Policy and Administration, Carleton University, Ottawa, ON, Canada.

\section{Acknowledgements}

Cooke is supported by NSERC and the Canada Research Chairs Program. Further support for the development of the ideas presented here was provided by Carleton University through their Research Excellence Fund. We thank Andrew Pullin and Neal Haddaway from the CEE for their assistance in developing an appetite and capacity for conducting systematic reviews in Canada.

\section{Competing Interests}

The authors declare that they have no competing interests. 


\section{Funding}

Natural Sciences and Engineering Research Council of Canada Discovery Grants to Cooke, Bennett and Vermaire. Canada Research Chair in Fish Ecology and Conservation Physiology to Cooke. Carleton University Research Excellence Fund to Cooke and Vermaire.

Received: 24 February 2016 Accepted: 21 June 2016

Published online: 18 July 2016

\section{References}

1. Bero L, Rennie D. The Cochrane Collaboration: preparing, maintaining, and disseminating systematic reviews of the effects of health care. JAMA. 1995:274(24):1935-8.

2. Pullin AS, Knight T. Effectiveness in conservation practice: pointers from medicine and public health. Cons Biol. 2001;15(1):50-4

3. Sutherland WJ, Pullin AS, Dolman PM, Knight TM. The need for evidencebased conservation. Trends Ecol Evol. 2004;19(6):305-8.

4. Pullin AS, Knight TM, Stone DA, Charman K. Do conservation managers use scientific evidence to support their decision-making? Biol Cons. 2004:119:245-52.

5. Popay J, Roberts H, Sowden A, Petticrew M, Arai L, Rodgers M, Britten N, Roen K, Duffy S. Guidance on the conduct of narrative synthesis in systematic reviews. Version 1. Lancaster University. Available from the Institute for Health Research. Lancaster: Lancaster University. 2006.

6. Pullin AS, Knight TM. Doing more good than harm-Building an evidencebase for conservation and environmental management. Biol Cons. 2009;142(5):931-4.

7. Fearon JD. Ethnic And Cultural Diversity By Country. J Econ Growth. 2003:8(2):195-222.

8. Newman, D. Natural Resource Jurisdiction in Canada. LexisNexis: Markham; 2013.

9. Garcia SM. Fishery science and decision-making: dire straights to sustainability. Bull Mar Sci. 2005:76:171-96.

10. Patterson K, Résimont M. Change and stability in landings: the responses of fisheries to scientific advice and TACs. ICES J Mar Sci. 2007:64:714-7.

11. Smith ADM, Sainsbury KJ, Stevens RA. Implementing effective fisheriesmanagement systems - management strategy evaluation and the Australian partnership approach. ICES J Mar Sci. 1999;56:967-79.

12. Butterworth DS, Punt AE. Experiences in the evaluation and implementation of management procedures. ICES J Mar Sci. 1999:56:985-98.

13. Minns CK. Science for freshwater fish habitat management in Canada: current status and future prospects. Aquat Ecosyst Health Manag. 2001;4(4):423-36
14. Goodchild GA. Fish habitat is everyone's business, Canada's fish habitat management programme. Fish Manage Ecol. 2004;11(3-4):277-81.

15. Minns CK, Randall RG, Smokorowski KE, Clarke KD, Vélez-Espino A, Gregory RS, Courtenay S, LeBlanc P. Direct and indirect estimates of the productive capacity of fish habitat under Canada's Policy for the Management of Fish Habitat: where have we been, where are we now, and where are we going? Can J Fish Aquat Sci. 2011:68:2204-27.

16. Rice J, Bradford M, Clarke KD, Koops MA, Randall RG, Wysocki R. The science framework for implementing the Fisheries Protection Provisions of Canada's Fisheries Act. Fisheries. 2015;40(6):268-75.

17. Spaling $\mathrm{H}$. Cumulative effects assessment: concepts and principles. Impact Asses. 1994;12:231-49.

18. Duinker PN, Grieg LA. The impotence of cumulative effects assessment in Canada: ailments and ideas for redeployment. Environ Manage. 2006;37:153-61.

19. Roberts PD, Stewart GB, Pullin AS. Are review articles a reliable source of evidence to support conservation and environmental management? A comparison with medicine. Biol Cons. 2006:132:409-23.

20. Cook CN, Mascia MB, Schwartz MW, Possingham HP, Fuller RA. Achieving conservation science that bridges the knowledge-action boundary. Cons Biol. 2013;27(4):669-78.

21. Pullin AS, Knight TM, Watkinson AR. Linking reductionist science and holistic policy using systematic reviews: unpacking environmental policy questions to construct an evidence-based framework. J Appl Ecol. 2009;46(5):970-5.

22. Lester NP, Marshall TR, Armstrong K, Dunlop WI, Ritchie B. A broad-scale approach to management of Ontario's recreational fisheries. N Am J Fish Manag. 2003;23:1312-28

23. Dicks LV, Walsh JC, Sutherland WJ. Organising evidence for environmental management decisions: a'4S'hierarchy. Trends Ecol Evol. 2014;29(11):607-13.

24. Arlettaz R, Schaub M, Fournier J, Reichlin TS, Sierro A, Watson JE, Braunisch V. From publications to public actions: when conservation biologists bridge the gap between research and implementation. Bioscience. 2010;60(10):835-42.

25. Berkes F. Traditional ecological knowledge in perspective. In: Inglis J, editor. Traditional ecological knowledge: concepts and cases. Ottawa: Canadian Museum of Nature; 1993. p. 1-9.

26. Raymond CM, Fazey I, Reed MS, Stringer LC, Robinson GM, Evely AC. Integrating local and scientific knowledge for environmental management. J Environ Manag. 2010;91(8):1766-77.

27. Pullin AS, Stewart GB. Guidelines for systematic review in conservation and environmental management. Cons Biol. 2006;20(6):1647-56.

28. Pullin AS, Bangpan $M$, Dalrymple $S$, et al. Human well-being impacts of terrestrial protected areas. Environ Evid. 2013;2:1-41.

\section{Submit your next manuscript to BioMed Central and we will help you at every step:}

- We accept pre-submission inquiries

- Our selector tool helps you to find the most relevant journal

- We provide round the clock customer support

- Convenient online submission

- Thorough peer review

- Inclusion in PubMed and all major indexing services

- Maximum visibility for your research

Submit your manuscript at www.biomedcentral com/submit
Ciomed Central 